UCRL-JC- 125426

PREPRINT

\title{
Non-equilibrium Energy Loss for Very Highly Charged Ions in Insulators
}

\author{
M. A. Briere \\ T. Schenkel \\ P. Bauer \\ A. Arnau
}

This paper was prepared for submittal to the Proceeding of Eighth International Conference on

Physics of Highly Charged Ions

Omiya, Saitama, Japan

September 23-26, 1996

October 30,1996

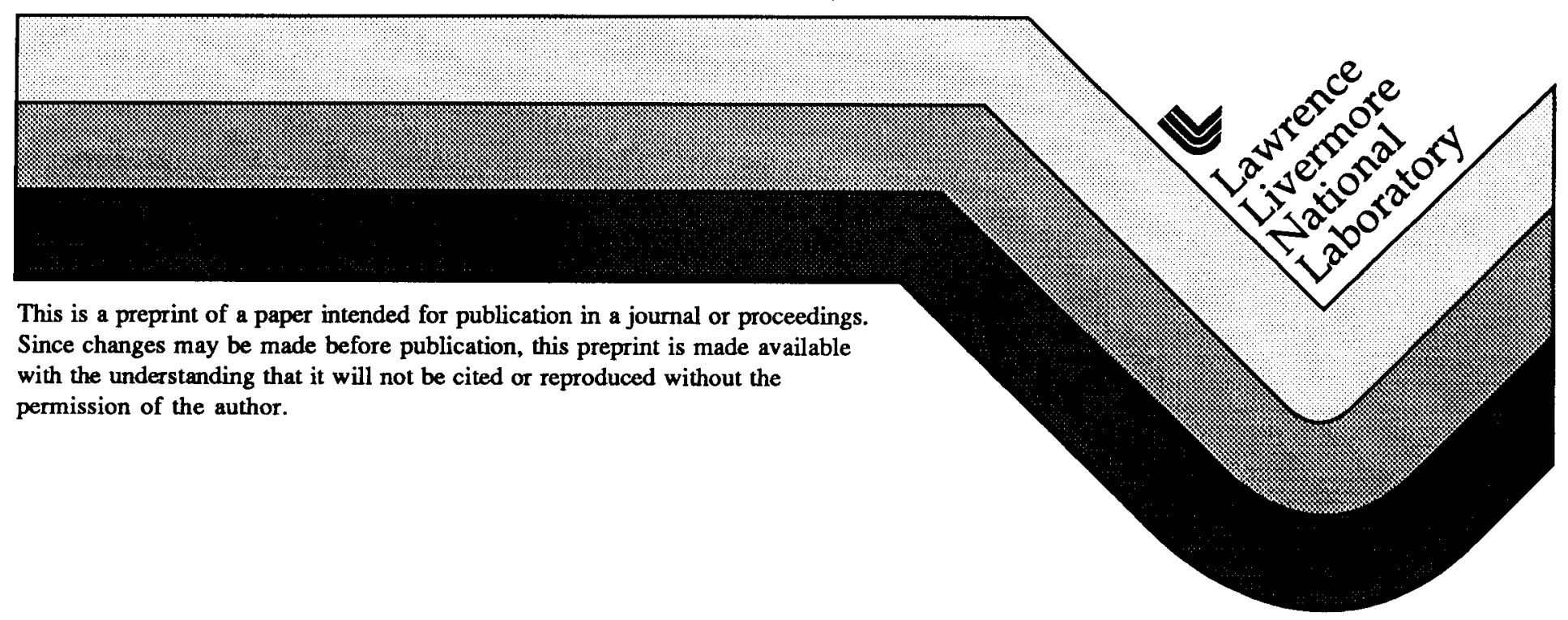




\section{DISCLAIMER}

This document was prepared as an account of work sponsored by an agency of the United States Government. Neither the United States Government nor the University of California nor any of their employees, makes any warranty, express or implied, or assumes any legal liability or responsibility for the accuracy, completeness, or usefulness of any information, apparatus, product, or process disclosed, or represents that its use would not infringe privately owned rights. Reference herein to any specific commercial product, process, or service by trade name, trademark, manufacturer, or otherwise, does not necessarily constitute or imply its endorsement, recommendation, or favoring by the United States Government or the University of California The viewa and opinions of authors expressed herein do not necessarily state or reflect those of the United States Government or the University of California, and shall not be used for advertising or product endorsement purposes. 


\title{
Non-equilibrium Energy Loss for Very Highly Charged tons in Insulators
}

\author{
M.A. Briere and T. Schenkel \\ Lawrence Livermore National Laboratory, Livermore CA 94550 USA \\ P. Bauer \\ Johannes-Kepler-Universitüt Linz, A-4(24O Linz, Austria
}

\begin{abstract}
A. Atnau
Departamento de Fisica de Materials, UPVIEHU, Donostia, Spain
\end{abstract}

The energy loss of $144 \mathrm{keV} \mathrm{Ax^{16+ }}$ ions on a bilayer structure of $\mathrm{C}^{-\mathrm{CaF}_{2}}$ has been measured. An asymmetry in the results is found depending on which layer is passed by the ion first: the energy loss is about four times larger when the $\mathrm{CaF}_{2}$ layer is traversed by the ion first. We interpret this as an indication of the existence of a nonequilibrium charge state of the Ar ions inside the solid in the case of the insulator. 
At present, it is unknown bow long very slow (keV/u) highly charged ions (i.e. $\mathrm{Ar}^{16+}, \mathrm{Kr}^{34+}, \mathrm{Th}^{80+}$ ) can retain a non-equilibrium charge state in solids. In fact, there is no evidence that even the inner shell vacancies of such ions exist beyond the furst few monolayers below the solid surface. Recently, it has been predicted that an increased nuclear-nuclear energy transfer, due to long range Coulomb interactions in insulators, is expected for these ions[1]. The object of our experiment is to demonstrate thal such an effect actually occurs. This is accomplished through differential transmission energy loss spectroscopy using ion time of flight, as shown in Figure 1. Previous attempts to measure such energy loss effects in $\mathrm{SiO}_{2}$, through highly sensitive RBS measurements of the projected range of $X e^{q+}$, where $1 \leq q \leq 44$, have produced negative results[2]. It is believed that this is due to the covalent nature of the insulator and therefore its screening of the ionic charge through strong polarization of the target atotus. A better candidate for the effect is a strong ionic solid such as $\mathbf{M g O}$ or $\mathrm{CaF}_{2}$. Furthermore, enhanced sensitivity to the effect would be achieved for transmission energy loss measurements through thin films, where the non-equilibrium state may exist over a large fraction of the ion's path length in the solid.

The differential technique is based upon the idea that the increased energy loss is expected only in ionic insulators (i.e. Cal? ${ }_{z}$ ) and not in metallic solids (i.e. C), since the valence electrons should efficiently screen the ion's potential at distances greater than the order of the lattice spacing. As depicted in Figure 2, a sandwich target structure is created under UHV conditions using thermal evaporation of several nanometers of $\mathrm{CaF}_{2}$ on a thin $(10 \mathrm{~nm})$ carbon foil backing, supported by a Cu TEM grid. Both AFM and TEM microscopic investigations indicate that the film is continuous for thickness of at least 2 to $4 \mathrm{~nm}$. The transmitted energy loss spectrum of highly charged ions (i.e. $\mathrm{Ar}^{16+}$ ) incident on the ionic solid (i.e. $\mathrm{CaF}_{2}$ ) side of the two layer target structure is compared to that for ions incident on the metallic (carbon) side. Measurements of the charge state distribution of the ions transmitted through $100 \mathrm{mn} \mathrm{C}$ foils indicate that charge state equilibrium is achieved within the foil 
(predominantly neutral and singly charged ions). Therefore, ions first passing through the $\mathrm{Cl}$ loil will interact with the $\mathrm{CsF}_{2}$ film in equilibrium, whereas ions first entering the insulator will experience non-equilibrium effects. An asymmetry in the results for the two cases, therefore, indicales the existence of a non-equilibrium charge state inside the solid. It should be noted that, energy loss measurements of $\mathbf{A r}^{16+}$ through various thickness of $\mathrm{C}$ loils are in excellent agreement with equilibrium data[3], confirming one of the basic assumptions of the technique. However, a significant increase in the transited energy loss for highly charged ions incident on ionic insulating targets has been observed. In the case of $144 \mathrm{keVAr}^{16+}$ ions $\mathrm{cm}$ a $5 \mathrm{~nm}$ $\mathrm{CaF}_{2}$ film, shown in Figure 3, the average energy loss for non-equilibrium charge states, $\delta \mathrm{E}_{2}$, is a factor of four greater than that for the equilibrium charge state, $\delta \mathrm{E}_{1}$, as achieved through initial transmission through a $10 \mathrm{~nm} \mathrm{C}$ foil. Additionally, a significant increase in the energy loss straggling is observed for the case of highly charged ions in ionic solids. Both the increased energy loss and the enhanced straggling are thought due to the influence of reduced screening for small impact parameter collisions on energy transfer cross sections, due to hollow atom formation in the solid. These results represent evidence for the existence of very slow highly charged ions inside solids and suggest several techniques to study the formation and decay of hollow atoms in solids. Measurements of this asymmetry in the energy loss can be used to deternine the average decay process of non-equilibrium charge states in solids. 
Acknowledgements

This work was performed under the auspices of the U.S. Dept. of Energy by the Lawrence Livermore National Laboratory under contract W-7405-ENG-48. One of us (A.A.) acknowledges partial financial support by Eusko Jaurlaritza and the spanish D.G.I.C.Y.T. 
References

[1] J.P. Bicrsack, Nucl. Insirum. Methods B80/81__12 (1993).

[2] MA. Briere et al., LINL EBIT Annual Report 1993, p. 33-35.

[3] R. Hertmann, CL. Cocke, J. Ulirich, S. Hagmann, M Stoeckli, and H. Schmidt-1\% vecking, Phys. Rev. A50, 1435 (1994). 
Figure captions

Figure 1: Expcrimental arrangement for the time-of-flight measurements of transmitted energy loss for incident highly charged ions. The annular micro-channel plate (MCP) detector, located in front of the sample, is used to detect electrons emitted at ion impact and provide a start signal to the time-to-amplitude converter (TAC). The large area MCP detector located beyond the target provides the stop signal for the time-c)f-flight of the ion and has a position sensitive anode, allowing for measurements of the scattered angle-energy correlation. The flight path is $0.75 \mathrm{~m}$ with a solid angle for the PS-MCP detector of $+/-1.5$ degrees.

Figure 2:A, schematic representation of the experimental technique for the differential energy loss determination. First, the transmitted energy (time-of-fLight) is measured for the bare $10 \mathrm{~nm} \mathrm{C}$ foil Then a film of $\mathrm{CaF}_{2}$ is deposited under UHV conditions. The transmitted energy is then measurcd for the ions incident on each of the two sides of the resulting hi-layer structure. The energy loss is determined directly from each side by subtraction of the bare $\mathrm{C}$ foil result,

Figure 3: Transmission time-of-flight results (converted into energy loss) for $\mathrm{Ar}^{16+}$ incident on the bare $10 \mathrm{~nm} \mathrm{C}$-foil $\left(\Delta \mathrm{E}_{0}\right.$, equilibrium) and the hi-layer structure: $\mathrm{C}$-side first $\left(\delta \mathrm{E}_{1}=\Delta \mathrm{E}_{1}-\Delta \mathrm{E}_{0}\right)$ and $\mathrm{CaF}_{2}$-side first $\left(\delta \mathrm{E}_{2}=\Delta \mathrm{E}_{2}-\Delta \mathrm{E}_{0}\right)$. A clear asymmetry exists between the results for the different incident sides of the same hi-layer structure, indicating nonequilibrium effects in the insulator. 


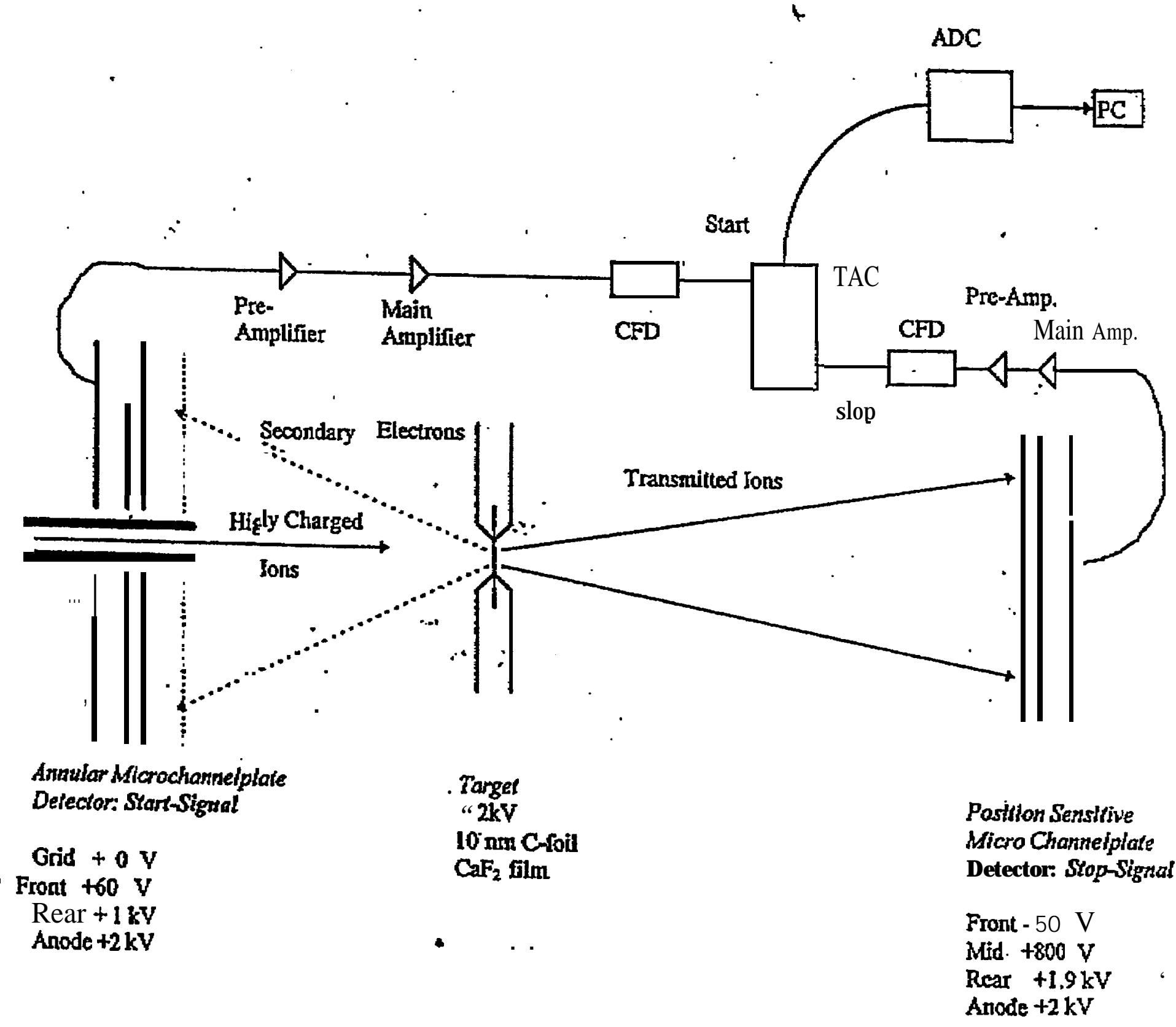



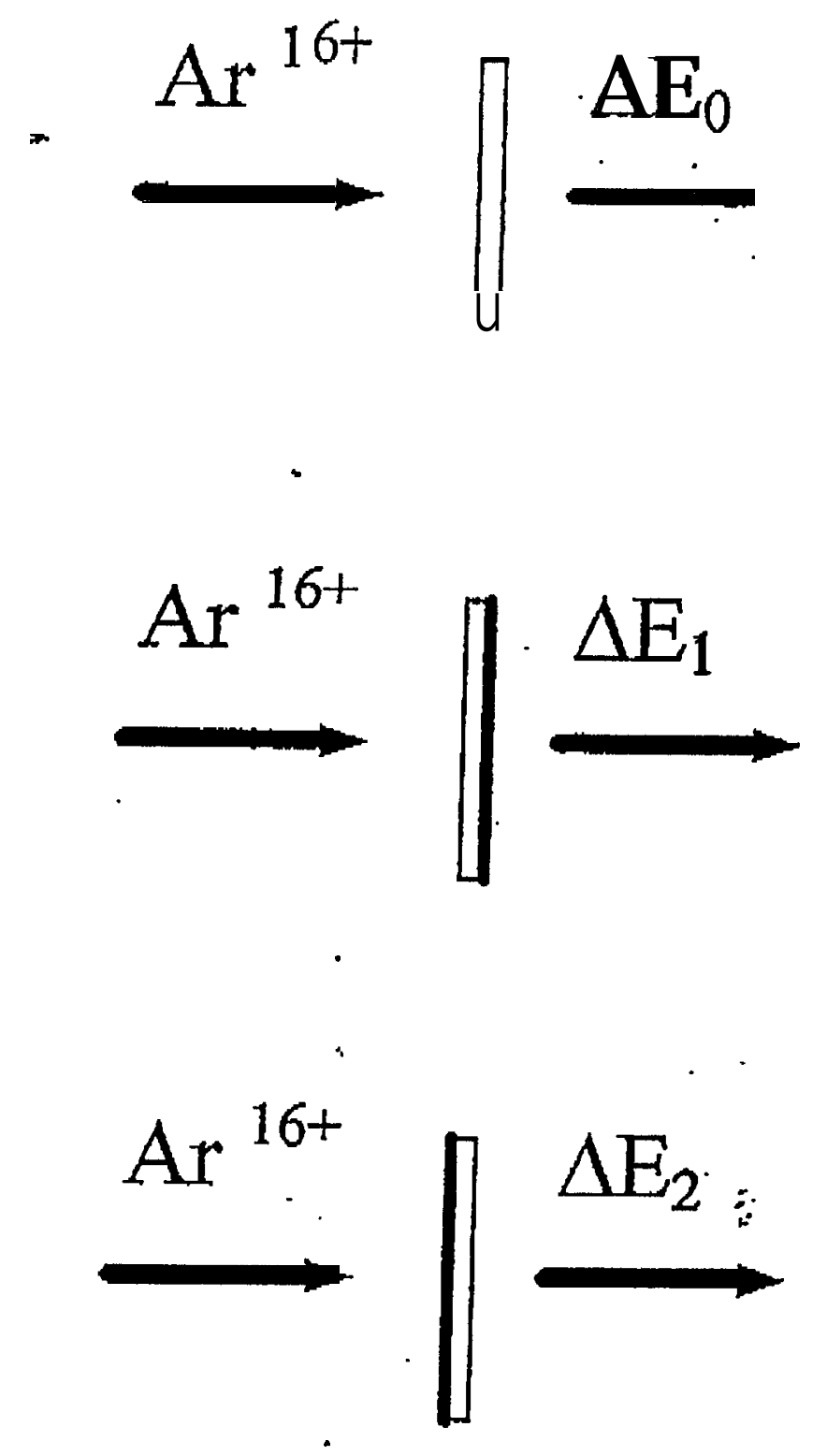

\section{$10 \mathrm{~nm} \mathrm{CFoil}$}

$\mathrm{CaF}_{2}$ Deposition

$10 \mathrm{~nm} \mathrm{C} / 5 \mathrm{~nm} \mathrm{CaF}_{2}$

1

$5 \mathrm{~nm} \mathrm{CaF} 2 / .10 \mathrm{~nm} \mathrm{C}$ 


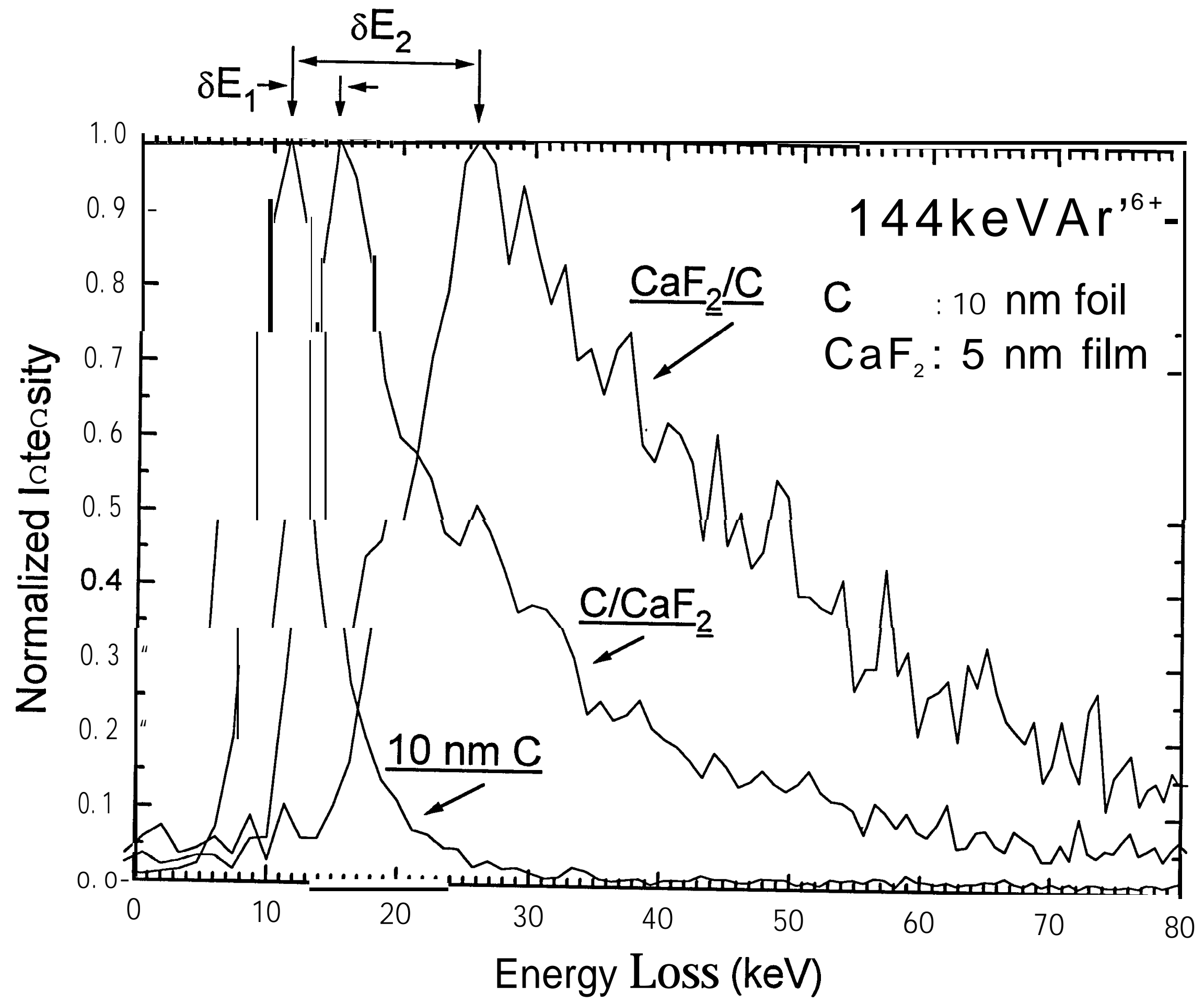




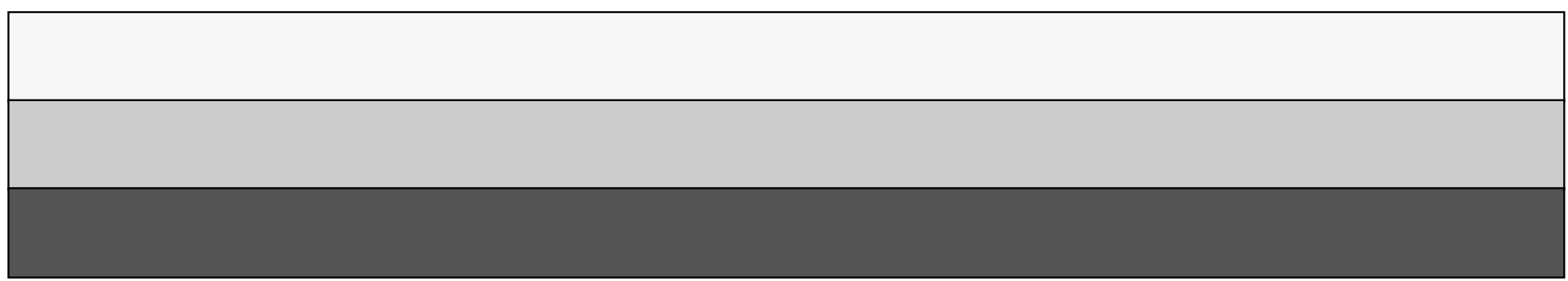

